\title{
Nutritional self-care in two older Norwegian males: a case study
}

This article was published in the following Dove Press journal:

Clinical Interventions in Aging

30 May 2013

Number of times this article has been viewed

\section{Solveig T Tomstad ${ }^{1,2}$ \\ Ulrika Söderhamn ${ }^{2}$ \\ Geir Arild Espnes ${ }^{1,3}$ \\ Olle Söderhamn²}

'Department of Social Work and Health Science, Faculty of Social Sciences and Technology Management, Norwegian University of Science and Technology, Trondheim, ${ }^{2}$ Centre for Caring Research-Southern Norway, Faculty of Health and Sport Sciences, University of Agder, Grimstad, ${ }^{3}$ Research Centre for Health Promotion and Resources, Department of Social Work and Health Science, Faculty of Social Sciences and Technology Management, Norwegian University of Science and Technology, Trondheim, Norway
Correspondence: Solveig T Tomstad Centre for Caring Research-Southern Norway, Faculty of Health and Sport Sciences, University of Agder, PO Box 509, NO-4898 Grimstad, Norway Tel +473723 3762

Email solveig.t.tomstad@uia.no
Background: Knowledge about how to support nutritional self-care in the vulnerable elderly living in their own homes is an important area for health care professionals. The aim of this case study was to evaluate the effects of nutritional intervention by comparing perceived health, sense of coherence, self-care ability, and nutritional risk in two older home-dwelling individuals before, during, and after intervention and to describe their experiences of nutritional self-care before and after intervention.

Methods: A study circle was established to support nutritional self-care in two older homedwelling individuals ( $\geq 65$ years of age), who participated in three meetings arranged by health professionals over a period of six months. The effects of this study circle were evaluated using the Nutritional Form For the Elderly, the Self-care Ability Scale for the Elderly (SASE), the Appraisal of Self-care Agency scale, the Sense of Coherence (SOC) scale, and responses to a number of health-related questions. Qualitative interviews were performed before and after intervention to interpret the changes that occurred during intervention.

Results: A reduced risk of undernutrition was found for both participants. A higher total score on the SASE was obtained for one participant, along with a slightly stronger preference for self-care to maintain sufficient food intake, was evident. For the other participant, total score on the SASE decreased, but the SOC score improved after intervention. Decreased mobility was reported, but this did not influence his food intake. The study circle was an opportunity to express personal views and opinions about food intake and meals.

Conclusion: An organized meeting place for dialogue between older home-dwelling individuals and health care professionals can stimulate the older person's engagement, consciousness, and learning about nutritional self-care, and thereby be of importance in reducing the risk of undernutrition.

Keywords: elderly, health promotion, intervention, study circle

\section{Introduction}

Studies have shown that older home-dwelling individuals value maintaining their independence and caring for themselves, ${ }^{1-3}$ suggesting that the elderly should be supported in independent living and self-care. ${ }^{1}$ It is also well known that old age may be accompanied by increasing health problems, which are often of a chronic nature. ${ }^{4}$ Most older people in Western societies, including the Nordic countries, live in their own homes, and often live alone..$^{5}$ In these parts of the world, it is desirable for older people to live in their own homes for as long as possible, and be supported by formal care, and locally based care if necessary. ${ }^{6}$

Living in one's own home in older age requires that older individuals take care of themselves. ${ }^{7}$ Orem ${ }^{8}$ describes self-care as the performance of activities that the person 
initiates and does on his/her own behalf to maintain health and well-being, and includes activities of daily living, such as preparation of and eating meals. ${ }^{9}$

Studies have identified groups of older home-dwelling people as being at nutritional risk, and living alone is highlighted as a particular risk factor. ${ }^{10-12}$ Further, it has been reported that the risk of undernutrition is increased in the elderly with chronic illness. ${ }^{13}$ Among older home-dwelling people, risk of undernutrition is also related to perceived ill health, ${ }^{11,12}$ receiving help, ${ }^{10,11}$ perceived helplessness, and inactivity. ${ }^{10}$ Older home-dwelling individuals identified to be at risk of undernutrition also report that their health problems can impair their social and physical activity, that being active is important to their health and well-being, and activity stimulates the appetite. Eating alone has been described as a challenging experience. ${ }^{3}$

Supporting nutritional self-care in the vulnerable elderly living in their own homes is considered important by health care professionals and is an important area of research. When supporting self-care in this age group, the elderly themselves are the key informants regarding their own health as well as contributors to their health-related circumstances. ${ }^{14}$ This perspective may be based upon health professionals considering the views of the elderly to be the most important when defining their own lives and needs, and letting them use their own words to represent themselves. ${ }^{15}$ Therefore, a meeting place, designed as a study circle, for the elderly and professionals from the health care services to come together may be of value in supporting daily nutritional self-care in older individuals.

The aim of this case study was to evaluate the effects of a nutritional intervention by comparing perceived health, sense of coherence, self-care ability, and nutritional risk in two older home-dwelling individuals before, during, and after intervention, and to describe their experiences of nutritional self-care before and after intervention. The specific research question was: how is it possible to support nutritional selfcare and reduce nutritional risk in older home-dwelling individuals?

\section{Subjects and methods}

To realize the aim and answer the research question, this research was designed as a case study based on an intervention. A case study design was considered to be important in studying the question of "how". ${ }^{16}$ By focusing on the individuals and using both qualitative interviews and quantitative self-report instruments, individual perspectives could be highlighted in the context of daily living ${ }^{16}$ and provide meaningful data about nutritional self-care in daily life and the potential effects of intervention.

\section{Participants}

Two men, referred to here as Andrew and Ben, were recruited with the assistance of a local home care service in a small municipality in Norway, and both met the inclusion criteria of being older than 65 years, able to participate in a study circle that included three meetings over a period of six months, answer a questionnaire before, during, and after intervention, and take part in a qualitative interview before and after intervention.

\section{Intervention}

In cooperation with the local home care service, a study circle was established to support and inform on nutritional self-care with the aim of reducing nutritional risk in older home-dwelling individuals. Health personnel from the home care service, ie, a nurse, an auxiliary nurse, and the leader of the kitchen at the local nursing home and day care center, were responsible for facilitating three meetings of the study circle during the spring of 2012.

The professionals responsible for the study circle were instructed and guided by the first and second authors, by written guidelines, literature, and meetings. A lesson was also given about being older and the risk of undernutrition.

The content of the meetings of the study circle were primarily based upon the participants' daily experience regarding food and meals. They could express how they experienced nutritional self-care and received advice from professionals or each other. The professionals also focused on special nutritional themes, including the preparation of attractive meals. Study circle meetings took place in February, March, and May 2012 at the nursing home and the day care center. Each meeting lasted about 1.5 hours and included a meal.

\section{Data collection \\ Questionnaire}

The questionnaire consisted of the Norwegian versions of the following instruments: the Nutritional Form For the Elderly (NUFFE), ${ }^{17-19}$ the Self-care Ability Scale for the Elderly (SASE), ${ }^{20-22}$ the Appraisal of Self-care Agency (ASA) scale, ${ }^{23}$ and the 29-item Sense of Coherence (SOC) scale. ${ }^{24}$ In addition to the instruments, the questionnaire included health-related questions about perceived health, receiving help, perceived meaningful life, helplessness, manageability, and comprehensibility, being active, perceiving a satisfying life, and adequacy of food intake. Such questions could be responded 
to with yes or no. Questions about height and weight were included, along with background characteristics such as age, civil status, type of residence, and previous occupation. The participants answered the questionnaire in December 2011 (before intervention), in April 2012 (during intervention), and in June 2012 (after intervention). Data collection was performed by the first author during home visits.

The NUFFE was originally developed to identify older individuals at nutritional risk and was tested in Sweden. ${ }^{17,18}$ The scale consists of items focusing on important factors related to being at risk for undernutrition, such as dietary history, dietary assessment, and assessment of ease of obtaining food products, company at meals, activity, and number of medications being taken. It is a summated ordinal scale and consists of 15 threepoint items. ${ }^{17,18}$ The score on each item ranges from 0 to 2 . The most disadvantageous option gives a score of 2 and the most advantageous option gives a score of 0 . Maximum score is 30. All items are displayed in the results. The instrument has been translated and tested in older Norwegian populations. ${ }^{19,22}$ Cutoff points $<6$, indicating lower risk of undernutrition, $\geq 6$, indicating medium risk of under nutrition, and $\geq 11$, indicating higher risk of undernutrition, were used. ${ }^{19}$

The SASE was developed as a self-reporting instrument to measure self-care ability among older persons. It has an attitude scale format based upon a construct of selfcare ability, including cognitive, affective, and behavioral components. The SASE is designed as a summated ordinal five-point Likert scale and includes 17 items dealing with activities of daily living, well-being, mastery and volition, determination, loneliness, and dressing. There are five response categories for each item, ranging from 1 (totally disagree) to 5 (totally agree). Four items are negatively stated and have to be reversed when the scores are summated. The maximum score is $85 .^{20,21}$ The original Swedish version of the SASE has been translated into the Norwegian language, and this version was also found to have satisfactory psychometric properties. A cutoff point $\leq 71$ indicates lower self-care ability and $\geq 72$ indicates higher self-care ability. ${ }^{22}$

The ASA measures self-care agency, that can be described as engagement and activation of power in self-care actions ${ }^{25,26}$ and reflects the self-care theory of Orem. ${ }^{8}$ It consists of 24 items and is a summated ordinal, bipolar Likert-type scale with five response categories for each item. The categories range from 1 (totally disagree), to 5 (totally agree). The highest score is 120 and the lowest 24 . Higher scores indicate higher self-care agency. Because nine items are negatively stated, they must be reversed in the summation..$^{25,26}$ The scale has been translated into the Norwegian language. ${ }^{23}$
The SOC scale was developed by Antonovsky ${ }^{24,27}$ to reflect the construct of a fundamental attitude in the sense of a dispositional orientation to life and includes three basic components, ie, comprehensibility, manageability, and meaningfulness. The scale consists of the constructs of comprehensibility (eleven items), manageability (ten items), and meaningfulness (eight items). Each of the items has a corresponding seven-point assessment scale, and there are 13 items that are negatively expressed and have to be reversed before summation. The highest score is 203, and the lowest is 29. A higher score indicates a stronger sense of coherence. ${ }^{24}$

\section{Interviews}

The qualitative interviews were performed by the first author in the participants' homes in February 2012 and June 2012. The same opening question was asked on both occasions. The interviewer asked the participants to describe their daily food intake and meals. Follow-up questions on that theme were then asked. The interviews lasted on average 40 minutes. The recorded interviews were transcribed verbatim.

\section{Data analyses Quantitative data}

Changes in health-related variables that occurred during and after the intervention were identified and described. The same procedure was used for weight. To evaluate the effects of the intervention, total scores for each measurement, ie, NUFFE, SASE, ASA, and SOC, were calculated. Score for all the items on the NUFFE before, during, and after intervention were registered. If changes occurred in the total score for the SASE, single items that appeared with changed scores after intervention were identified and described.

\section{Qualitative data}

The transcribed interviews with each participant were analyzed using the qualitative content analysis described by Graneheim and Lundman. ${ }^{28}$ The entire text was read first, then reread and broken into meaning units. The meaning units were condensed, while retaining the core. Creating categories that shared commonalities was the next step. ${ }^{28}$ Regarding the underlying content of the text, ${ }^{28}$ the content of the categories of both interview texts for each participant was used as the basis for interpretation of changes regarding nutritional issues that occurred, from a self-care perspective.

\section{Ethical considerations}

This research was designed and performed in accordance with the principles outlined in the Declaration of 
Helsinki ${ }^{29}$ concerning autonomy, justice, beneficence, and nonmaleficence. ${ }^{30}$ The study was approved by the Regional Committee for Medical Research Ethics in Southern Norway (REK Sør-Øst B, registration number 2011/1344B), and by the Norwegian Social Science Data Services (project number 28183).

\section{Results}

Background and health-related variables of participants before, during, and after intervention

Andrew was in his early seventies and lived alone in a flat. He received help from his family, and had home nursing and home help. Andrew was not in good health before, during, or after the intervention. His life was not satisfying and he was not an active person before intervention. After intervention, he reported that life was more satisfying and that he was an active person. A change also occurred after the intervention in terms of perceiving lack of comprehensibility concerning all that happens in daily life.

Ben was in his late seventies, and lived alone in a flat. He did not receive help from his family, but did receive home nursing and home help. He perceived life as satisfying and he was in good health before, during, and after intervention. However, he reported increasing health problems after intervention. He was an active person before, during, and after intervention, but expressed a slight reservation regarding activity level after intervention.

\section{Measurements with instruments before, during, and after intervention}

Measurements on the NUFFE, SASE, ASA and SOC are presented for each participant in Table 1 as total scores for each instrument before, during, and after intervention. Scores on items in the NUFFE are shown in Table 2 for Andrew and in Table 3 for Ben.

With regard to changes in SASE items, Andrew obtained higher scores after the intervention than before on items such as dental care $(+1)$, adequate mobility $(+1)$, strength $(+3)$, desire to manage alone $(+2)$, and managing alone $(+1)$. A decreased score appeared regarding being able to go to places that are not within walking distance $(-1)$.

Ben obtained a moderately higher score after intervention on the item about desire to manage his own housekeeping $(+1)$. However, lower scores were obtained on several items, eg, being able to go to places that are not within walking distance $(-1)$, adequate mobility $(-1)$, and safety when moving in his own environment $(-2)$. Items concerning feeling satisfied with life $(-1)$ and strength $(-3)$ also had lower scores after intervention. Measurements of height and weight for each participant before, during, and after intervention are presented in Table 4.

\section{Health and self-care narrated by Andrew Living with health problems}

Andrew reported that he had lived with health problems for several years. He had to take several medicines that interfered with his food intake, and he was not able to eat first thing in the morning. He had previously experienced a weight loss of several kilograms. His appetite had decreased, but he said he had to eat. "There is not much I'd like, but I have to eat." Further, his particular health problems required an awareness of daily food intake and meals, and this was a challenge for him. "Everything that I enjoy I am not allowed to eat."

Andrew also lived with health problems that were perceived as painful and limiting, and increasing oral health problems were a challenge in his daily life and interfered with his food intake. Being able to obtain professional help for oral health problems was important to him. However, working

Table I Total scores on the NUFFE, SASE, ASA and SOC before, during, and after intervention for the two participants known as Andrew and Ben

\begin{tabular}{lllll}
\hline Participants & Instruments & $\begin{array}{l}\text { Scores before } \\
\text { intervention }\end{array}$ & $\begin{array}{l}\text { Scores during } \\
\text { intervention }\end{array}$ & $\begin{array}{l}\text { Scores after } \\
\text { intervention }\end{array}$ \\
\hline Andrew & NUFFE (0-30) & 14 & 11 & 11 \\
& SASE (17-85) & 70 & 77 & 78 \\
& ASA (24-120) & 96 & 97 & 94 \\
Ben & SOC (29-203) & 159 & 159 & 152 \\
& NUFFE (0-30) & 4 & 3 & 3 \\
& SASE (17-85) & 78 & 75 & 71 \\
& ASA (24-120) & 103 & 99 & 102 \\
\hline
\end{tabular}

Abbreviations: NUFFE, Nutritional Form For the Elderly; SASE, Self-care Ability Scale for the Elderly; ASA, Appraisal of Self-care Agency scale; SOC, Sense of Coherence scale. 
Table 2 NUFFE items with changes in response alternatives before, during, and after intervention, and items with stable higher scores for the participant known as Andrew

\begin{tabular}{|c|c|c|c|}
\hline NUFFE items and response alternatives with scores & Before intervention & During intervention & After intervention \\
\hline \multicolumn{4}{|l|}{ Has your weight changed in the past 12 months? } \\
\hline Weight has either gone up or remained unchanged $(0)$ & & $x$ & \\
\hline Weight has dropped somewhat (I) & $x$ & & $x$ \\
\hline \multicolumn{4}{|l|}{ Weight has dropped considerably (2) } \\
\hline \multicolumn{4}{|l|}{ Do you eat the same amount of food now as you did a year ago? } \\
\hline More or the same as previously $(0)$ & & $x$ & $x$ \\
\hline \multicolumn{4}{|l|}{ Somewhat less than previously (I) } \\
\hline Considerably less than previously (2) & $x$ & & \\
\hline \multicolumn{4}{|l|}{ What is your appetite now? } \\
\hline Good $(0)$ & & $x$ & $x$ \\
\hline Somewhat low (I) & $x$ & & \\
\hline \multicolumn{4}{|l|}{ Poor (2) } \\
\hline \multicolumn{4}{|l|}{ Do you eat at least one cooked meal/day? } \\
\hline Yes, always (0) & $x$ & $x$ & $x$ \\
\hline \multicolumn{4}{|l|}{ Often $(I)$} \\
\hline \multicolumn{4}{|l|}{ Seldom (2) } \\
\hline \multicolumn{4}{|l|}{ What size portions do you normally eat? } \\
\hline Large or ordinary portions $(0)$ & & $x$ & $x$ \\
\hline Fairly small portions (I) & $x$ & & \\
\hline \multicolumn{4}{|l|}{ Very small portions (2) } \\
\hline \multicolumn{4}{|l|}{ Do you eat food or vegetables on a daily basis? } \\
\hline \multicolumn{4}{|l|}{ Yes $(0)$} \\
\hline \multicolumn{4}{|l|}{ Often $(I)$} \\
\hline Seldom (2) & $x$ & $x$ & $x$ \\
\hline \multicolumn{4}{|l|}{ Do you have the types of food that you need at home? } \\
\hline Yes $(0)$ & $x$ & $x$ & $x$ \\
\hline \multicolumn{4}{|l|}{ Often (I) } \\
\hline \multicolumn{4}{|l|}{ Seldom (2) } \\
\hline \multicolumn{4}{|l|}{ Do you normally eat together with someone else? } \\
\hline Yes $(0)$ & $x$ & & \\
\hline \multicolumn{4}{|l|}{ Sometimes (I) } \\
\hline Very seldom (2) & & $x$ & $x$ \\
\hline \multicolumn{4}{|l|}{ Do you get exercise every day? } \\
\hline I exercise a lot, for example taking walks $(0)$ & & & $x$ \\
\hline The only exercise I get is indoors (I) & $x$ & $x$ & \\
\hline Mostly I just sit down or lie in bed (2) & & & \\
\hline Is it difficult for you to eat because of mouth or dental probl & & & \\
\hline or due to difficulties in swallowing? & & & \\
\hline No $(0)$ & & & \\
\hline Sometimes (I) & & & \\
\hline Yes, often (2) & $x$ & $x$ & $x$ \\
\hline How much liquid do you drink in total per day? & & & \\
\hline More than 5 glasses/cups per day $(0)$ & $x$ & $x$ & $x$ \\
\hline 3-5 glasses/cups per day (I) & & & \\
\hline Fewer than 3 glasses/cups per day (2) & & & \\
\hline Do you have problems eating due to diarrhea, constipation, & & & \\
\hline feeling unwell or nausea? & & & \\
\hline No $(0)$ & & & \\
\hline Sometimes (I) & $x$ & & $x$ \\
\hline Yes, often (2) & & $x$ & \\
\hline Do you need help eating? & & & \\
\hline No $(0)$ & $x$ & $x$ & $x$ \\
\hline Sometimes (I) & & & \\
\hline Yes, often (2) & & & \\
\hline
\end{tabular}


Table 2 (Continued)

\begin{tabular}{|c|c|c|c|}
\hline NUFFE items and response alternatives with scores & Before intervention & During intervention & After intervention \\
\hline \multicolumn{4}{|l|}{ How many sorts of medicine do you take per day? } \\
\hline \multicolumn{4}{|l|}{ None (0) } \\
\hline \multicolumn{4}{|l|}{$\mathrm{I}-2$ different medicines/day $(\mathrm{I})$} \\
\hline 3 or more different medicines/day (2) & $x$ & $x$ & $x$ \\
\hline \multicolumn{4}{|l|}{ Is it difficult for you to eat as a result of poorer health? } \\
\hline No $(0)$ & & $x$ & \\
\hline Sometimes (I) & $x$ & & $x$ \\
\hline Yes, often (2) & & & \\
\hline
\end{tabular}

Abbreviation: NUFFE, Nutritional Form For the Elderly.

towards a sufficient and healthier food intake was particularly focused on in the second interview.

\section{Food choices and meals}

Andrew reported that making special effort regarding food choices in the morning was a positive experience. Family members also gave advice regarding food choices and health.

However, Andrew was able to prepare all his meals himself if he wanted, and considered himself to be a good cook. If he needed advice, he could call on his extended family. He preferred home-cooked meals. But, because he was living alone, he ate more fast foods. However, he considered that food did not taste good whether prepared carefully by himself or if it was fast food. "It does not taste good irrespective of what I eat. This is also the case, even if I have prepared the food myself."

Andrew was eating dinner every day, but not at set hours. He organized his meals as he pleased and did not give preference to specific times, nor sit down at every meal. He referred to the meetings in the project and recalled that one of the health professionals and the other participant had underlined the importance of having attractive meals. Further on, he mentioned that the health professional spoke in a comprehensible way. When having increasing oral health problems, Andrew worked towards having an adequate food intake. He planned to go to the day care center to eat dinner once a week when he had received treatment for his oral health problems.

\section{Level of daily activity}

When the weather was fine, Andrew preferred to take a morning walk around the neighborhood. He was aware that it was necessary to eat beforehand. He had a motorized wheelchair, but slippery roads limited his mobility. However, living alone, he felt he could do what he wanted. He felt that to sleep on the sofa was okay. If he became tired, he often preferred to rest. He developed headaches from watching television, and did not read. He had knowledge about the many local activities available for older persons, and previously had been more active, but still visited the day care center often for a cup of coffee. He had previously enjoyed travelling to a health care center abroad where he was able to be more mobile.

\section{Social networks}

Having regular short visits from family members for a cup of coffee in the mornings was perceived as important support for facing the day. Others in the family would visit him in the afternoons, and he could call the family if needed. Andrew also greeted other family members who usually passed his residence in the mornings. If he did not, they called him. He had always experienced support from his family, and he perceived that they still readily supported him. "And they continue to do that. Either they visit me, or I visit them."

Andrew had a strong sense of local belonging and good memories, and was well known in his neighborhood, but wished to have more visitors. When his wife was alive, their friends often came for coffee, but less so after her death; however, he still had friends to visit, and he met people on his trips to the day care center. With his decreasing oral health, he preferred not to have company at mealtimes.

\section{Receiving help}

Andrew reported being helped to feel safe by daily visits from local health care personnel. In addition to his family members, health personnel could buy his groceries if there were any barriers to him doing that himself, such as slippery roads. Andrew also reported that he could call in for dinner at the day care center if he was sick. He had a safety alarm, and he was confident that he would get help at once if it was 
Table 3 NUFFE items with changes in response alternatives before, during, and after intervention, and items with stable higher score for the participant known as Ben

\begin{tabular}{|c|c|c|c|}
\hline NUFFE items and response alternatives with scores & Before intervention & During intervention & After intervention \\
\hline \multicolumn{4}{|l|}{ Has your weight changed in the past 12 months? } \\
\hline Weight has either gone up or remained unchanged $(0)$ & & $x$ & $x$ \\
\hline Weight has dropped somewhat (I) & $x$ & & \\
\hline \multicolumn{4}{|l|}{ Weight has dropped considerably (2) } \\
\hline \multicolumn{4}{|l|}{ Do you eat the same amount of food now as you did a year ago? } \\
\hline More or the same as previously $(0)$ & $x$ & $x$ & $x$ \\
\hline \multicolumn{4}{|l|}{ Somewhat less than previously (I) } \\
\hline \multicolumn{4}{|l|}{ Considerably less than previously (2) } \\
\hline \multicolumn{4}{|l|}{ What is your appetite like now? } \\
\hline Good $(0)$ & $x$ & $x$ & $x$ \\
\hline \multicolumn{4}{|l|}{ Somewhat low (I) } \\
\hline \multicolumn{4}{|l|}{ Poor (2) } \\
\hline \multicolumn{4}{|l|}{ Do you eat at least one cooked meal/day? } \\
\hline Yes, always (0) & $x$ & $x$ & $x$ \\
\hline \multicolumn{4}{|l|}{ Often $(I)$} \\
\hline \multicolumn{4}{|l|}{ Seldom (2) } \\
\hline \multicolumn{4}{|l|}{ What size portions do you normally eat? } \\
\hline Large or ordinary portions $(0)$ & $x$ & $x$ & $x$ \\
\hline \multicolumn{4}{|l|}{ Fairly small portions (I) } \\
\hline \multicolumn{4}{|l|}{ Very small portions (2) } \\
\hline \multicolumn{4}{|l|}{ Do you eat fruit or vegetables on a daily basis? } \\
\hline Yes $(0)$ & $x$ & $x$ & $x$ \\
\hline \multicolumn{4}{|l|}{ Often $(I)$} \\
\hline \multicolumn{4}{|l|}{ Seldom (2) } \\
\hline \multicolumn{4}{|l|}{ Do you have the types of food that you need at home? } \\
\hline Yes $(0)$ & $x$ & $x$ & $x$ \\
\hline \multicolumn{4}{|l|}{ Often (I) } \\
\hline \multicolumn{4}{|l|}{ Seldom (2) } \\
\hline Do you normally eat together with someone else? & & & \\
\hline Yes $(0)$ & $x$ & $x$ & $x$ \\
\hline Sometimes (I) & & & \\
\hline Very seldom (2) & & & \\
\hline Do you get exercise every day? & & & \\
\hline I exercise a lot, for example taking walks $(0)$ & & & \\
\hline The only exercise I get is indoors (I) & $x$ & $x$ & $x$ \\
\hline Mostly I just sit down or lie in bed (2) & & & \\
\hline Is it difficult for you to eat because of mouth or dental probl & & & \\
\hline or due to difficulties in swallowing? & & & \\
\hline No $(0)$ & $x$ & $x$ & $x$ \\
\hline Sometimes (I) & & & \\
\hline Yes (2) & & & \\
\hline How much liquid do you drink in total per day? & & & \\
\hline More than 5 glasses/cups per day $(0)$ & $x$ & $x$ & $x$ \\
\hline $3-5$ glasses/cups per day $(I)$ & & & \\
\hline Fewer than 3 glasses/cups per day (2) & & & \\
\hline Do you have problems eating due to diarrhea, constipation, & & & \\
\hline feeling unwell or nausea? & & & \\
\hline No $(0)$ & $x$ & $x$ & $x$ \\
\hline Sometimes (I) & & & \\
\hline Yes, often (2) & & & \\
\hline Do you need help eating? & & & \\
\hline No $(0)$ & $x$ & $x$ & $x$ \\
\hline Sometimes (I) & & & \\
\hline Yes, often (2) & & & \\
\hline
\end{tabular}


Table 3 (Continued)

\begin{tabular}{|c|c|c|c|}
\hline NUFFE items and response alternatives with scores & Before intervention & During intervention & After intervention \\
\hline \multicolumn{4}{|l|}{ How many different sorts of medicine do you take per day? } \\
\hline \multicolumn{4}{|l|}{ None $(0)$} \\
\hline \multicolumn{4}{|l|}{$\mathrm{I}-2$ different medicines/day $(\mathrm{I})$} \\
\hline 3 or more different medicines/day (2) & $x$ & $x$ & $x$ \\
\hline \multicolumn{4}{|l|}{ Is it difficult for you to eat as a result of poorer health? } \\
\hline No $(0)$ & $x$ & $x$ & $x$ \\
\hline \multicolumn{4}{|l|}{ Sometimes (I) } \\
\hline Yes, often (2) & & & \\
\hline
\end{tabular}

Abbreviation: NUFFE: Nutritional Form For the Elderly.

needed. He could also go to his doctor or to the day care center when necessary.

\section{Orientation to life}

Facing each day as it came was considered to be a useful attitude to life. He was mostly satisfied. If his life situation changed in the future, he was prepared to move to the local nursing home, which he knew well.

\section{Changes pertaining to the intervention}

from a self-care perspective

Performing daily activities, including food choices and meals, was based on varied preferences depending upon the actual situation. Health problems, such as deteriorating oral health, chronic illness, and his medication regimen influenced his daily food intake. Reflection on possibilities for organized meals was encouraged, including consideration of the nutritional information communicated in the study circle. Andrew had a stronger preference for self-care in the maintenance of adequate food intake, despite his health problems.

\section{Health and self-care narrated by Ben Facing changes in life}

Ben experienced changes in his life situation when his wife became seriously ill, and losing her some years ago resulted in a sense of insecurity. The simple act of preparing meals together at home and having company at mealtimes had gone, and he experienced a sense of loneliness. Living alone was seen as a challenge that had demanded rethinking his routines of daily living, so Ben had decided to increase his participation at the day care center. "To sit back and stare out of the window was not my style. Therefore, I increased my participation there." However, Ben had been prepared for the fact that his life situation could change, and he felt that this had helped him to adapt to this change. Although he missed his wife, when living alone he had only himself to take care of on a day-to-day basis.

\section{Planned days}

Ben considered it important to have an organized daily program that included set times for meals and activities. Every day Ben ate a meal at the local health center, which also included activity. Other meals he had at home at set hours. Organizing the days, including mealtimes, made life simpler for him. "My day is complicated and simple, simple because I eat dinner every day at the day care center."

\section{Awareness of food choices and meals}

Having dinner on most days at the local health center, Ben felt that he was eating wholesome food. He reported that the cook was actively engaged in preparing and serving food that, for example, included fish several times a week. "The leader of the kitchen underlines the importance of eating fish, and I agree with that. Fish dishes are served weekly up to three times, and also there is well tasting and varied food." Dinner there also included dessert, coffee, and cake, and Ben was pleased with the service provided.

However, if he was having a bad day, Ben could ask for his dinner to be delivered to his flat. Preparing other meals at home was simple, because he mostly prepared meals consisting of sandwiches, coffee, milk, juice, and fruit.

Table 4 Measurements of height and weight for the two participants known as Andrew and Ben

\begin{tabular}{lllll}
\hline Participants & Height & $\begin{array}{l}\text { Weight before } \\
\text { intervention }\end{array}$ & $\begin{array}{l}\text { Weight during } \\
\text { intervention }\end{array}$ & $\begin{array}{l}\text { Weight after } \\
\text { intervention }\end{array}$ \\
\hline Andrew & $175 \mathrm{~cm}$ & $95 \mathrm{~kg}$ & $100 \mathrm{~kg}$ & $99 \mathrm{~kg}$ \\
Ben & $176 \mathrm{~cm}$ & $73 \mathrm{~kg}$ & $74 \mathrm{~kg}$ & $74.5 \mathrm{~kg}$ \\
\hline
\end{tabular}


He bought his food at a local shop, and could walk the distance required and carry his groceries with the help of a walker. Ben was aware of choosing food that tasted good, and appreciated being able to prepare attractive meals and having the time to enjoy them. When he did not eat enough, he did not feel well.

\section{Living with health problems}

Ben had complex health problems and reported that these increasingly impaired his mobility. He needed a wheeled walker when moving outside, but he could drive his car for a longer distance. Ben's approach was to seek professional help regarding his health problems, but also to accept that his mobility had decreased and that he needed to adapt accordingly. However, he reported that his health problems did not impact negatively on his appetite.

\section{Asking for and receiving help if needed}

Ben considered that an important aspect of safety in old age included living in a place where help was readily available if needed. Previously, he had used his safety alarm, and reported that local health personnel came immediately. He also mentioned that he could call them and ask for a visit if necessary, which could include having dinner brought to his home.

\section{Social connections}

Ben had mastered living alone. However, he spoke of the importance of being in contact with other people. For him, it was important to eat dinner every day with other people at the health center. "To eat alone is a dreary business." At the health care center, Ben met people with similar experiences. These gatherings were important for his mental health, his engagement with others, and the opportunity to help other people. His family did not live nearby. Belonging to a church was also a part of his social network, but increasing health problems limited how often he was able to go to meetings there.

\section{Being active and engaged}

Ben was aware of being active according to his health limitations. He appreciated the three hours he spent every day at the health center, where he could help with setting the table and washing the dishes. This was also a place where he could be helpful to others.

At home, Ben spent time reading books and watching television. Keeping abreast of news was important to him. Sometimes he took a trip in his car, but he felt that his desire to travel had decreased in older age. He received regular help with housework, but preferred to do the more simple housework himself. Every day he did physical exercises at home to maintain his mobility.

Ben valued participating in the self-care project meetings. He considered these as an opportunity to have a voice. "I have said what I wanted to say." However, he would have liked to have a compendium containing the meeting program.

\section{Orientation to life}

Ben reported that he was satisfied with his present daily life. His Christian faith provided safety regarding the future, and this orientation also meant a change in how he considered other people and engaged with others.

\section{Changes pertaining to the intervention from a self-care perspective}

Ben felt that maintaining a balance between his physical capacity and goals regarding daily activities including meals was important, but reported a deterioration in his mobility. His health problems did not affect his appetite. The study circle was considered an opportunity to express his personal views and opinions about food intake and meals in old age. However, he would have preferred to have a written compendium outlining the themes discussed in the study circle.

\section{Discussion}

In this case study, we examined the effects and changes occurring in a nutritional intervention based on the concept of self-care. The main question to be answered was how to support nutritional self-care and reduce nutritional risk in two older home-dwelling individuals.

The study circle intervention in the present study was primarily focused on the participants' experiences of nutritional self-care in their daily lives. An important source of information about nutritional needs and possible challenges of daily life in the elderly is the elderly themselves, ${ }^{31}$ and to support self-care in older age, health personnel need to facilitate thought processes in the elderly. Therefore, dialogue between the elderly and health professionals is important, ${ }^{32}$ and is feasible in a study circle. Further, it can be argued that no knowledge can be gained without referring to consciousness, ${ }^{33}$ for which there is an opportunity within a study circle, which may also be helpful when evaluating the changes and effects of an intervention based upon narratives and self-reported data.

Andrew reported that obtaining adequate nutrition in daily life was a problem. He described a complex situation 
regarding food intake and meals influenced by chronic illness, substantial medicine intake, and decreasing oral health. He had suffered significant weight loss, and food did not taste good. He also reported not being in good health, and before the intervention he was neither satisfied with this nor active. Nutritional screening identified Andrew to be at risk of undernutrition. Chronic illness and polypharmacy are known to have a negative influence on eating habits in older people. ${ }^{34}$ Inability to chew properly has also been reported to be a risk factor for undernutrition. ${ }^{35}$ However, it is well known that being old and having nutritional problems is a complex issue, and may be related to somatic, psychic, and social problems. ${ }^{35}$ This should be borne in mind when evaluating the changes and effects of the intervention used in the present study.

Andrew valued the freedom to spend his days as he wanted and to take life day by day. He did not attach importance to having regular meals. Food restrictions were reported as difficult, and spending time preparing attractive meals was not prioritized. However, Andrew did reflect on information communicated in the study circle about spending more time preparing palatable meals. Of note, he valued dialogue with a health professional who talked in a way he could understand, and an ability to do this may depend on the interpersonal skills of the health professional. ${ }^{14}$

Another advantage of the study circle was the opportunity to learn from others, and Andrew reflected on Ben's experiences regarding food intake and meals. Learning from others may be a fruitful way to be engaged and involved in self-care by learning how other people handle similar problems. ${ }^{32}$ In the study circle, there was the opportunity to share stories about self-care, including food intake and preparation of meals. Such stories may also serve as a map enabling a person to reflect on the past, the present, and what changes might be made in the future. ${ }^{14}$ For example, Andrew had entered a more constructive phase regarding nutritional self-care during the intervention, including a plan to have dinner at the day care center once a week.

This positive process was confirmed by Andrew's scores on the NUFFE, showing a reduction in risk of undernutrition after intervention. However, Andrew's body weight was measured to be relatively and consistently high, although he reported weight loss before and after intervention. Going solely on the basis of weight, Andrew may well have been overnourished, but the NUFFE scores showed a risk of undernutrition. This paradox is actually possible. ${ }^{36}$ Identifying undernutrition at an early stage, including unintentional weight loss, among older persons with high body weight may be a challenge, but is important. ${ }^{36,37}$ After the intervention, Andrew also reported being more active, and this would be a positive factor regarding nutritional self-care. ${ }^{3,10}$

Measurements of ability to self-care showed that Andrew had the potential to perform such activities. However, the item on the SASE with the greatest increase in score after the intervention was about recognition of how little strength he had. It is also interesting that he reported less understanding of what happened in daily life after the intervention. This selfknowledge may be of importance to Andrew's self-care in the future. Andrew also had a sense of safety which stemmed from being supported by his family. However, his scores on the SASE indicated a stronger desire to manage alone. His decision to eat dinner at the day care center may be promising regarding his nutritional self-care.

Ben undertook activities of daily living that are in line with what studies have shown to be important regarding good nutritional self-care. Ben was aware of his food choices and attached importance to having attractive meals. He also appreciated the social aspects of eating dinner at the day care center, and valued being active and engaged with other people. It has been reported that social contact may protect against nutritional risk $^{38}$ and stimulate the appetite. ${ }^{3}$ Being active and engaged ${ }^{3}$ have also been found to be important in nutritional self-care. Ben highlighted his social engagement at the day care center as important for his mental well-being, and this is again consistent with the literature. ${ }^{39}$

Knowledge of self and one's environment is considered to be of importance in effective self-care. ${ }^{8}$ Ben was aware of the balance between these aspects. However, he reported increasing health problems and decreasing mobility. His scores on the SASE decreased after the intervention, in particular for items on mobility in the environment and physical strength. However, he reported that his increasing health problems did not influence his food intake. After the intervention, slightly increasing body weight was recorded. His NUFFE scores suggested a low risk of undernutrition, showing a slight decrease during and after intervention.

To participate in the study circle might have stimulated Ben's ability to be engaged. Here, he had an opportunity to have a voice and address the themes he considered to be important regarding food intake and meals, and to relate his experiences. Fenge ${ }^{15}$ underscored the importance of putting the voice of older persons on the agenda and letting them speak for themselves, and this was particularly relevant for Ben in view of his increased score on the SOC after intervention. A high SOC score might indicate a strong 
potential to invest engagement in what happens in daily life. ${ }^{24}$ It can be argued that to be able to perform useful self-care activities, a person has to possess the relevant knowledge, ${ }^{40}$ which Ben was probably aware of when suggesting a written compendium containing the nutritional themes discussed.

However, the other participant referred to Ben's experiences regarding preparing meals. It is possible that Ben gained a favorable position in the group. Consequently, it is possible that his negative outcome regarding self-care ability was a result of unawareness of his decreasing health and impaired mobility.

For a case study, the goal is not to generalize the findings to a population, but rather to arrive at theoretical propositions, ${ }^{16}$ which, in the case of the present study, concerns how to support nutritional self-care and reduce the risk of undernutrition among the home-dwelling elderly.

\section{Conclusion}

The results of this study indicate that an organized meeting place for dialogue between the home-dwelling elderly and health care professionals can stimulate engagement, consciousness, and knowledge about nutritional self-care in older people, and be of importance in reducing the risk of undernutrition.

\section{Acknowledgments}

The authors are grateful to the informants and to health professionals who contributed to this study. The study was supported by funds from two county councils, West Agder and East Agder, in southern Norway.

\section{Disclosure}

The authors report no conflicts of interests in relation to this work.

\section{References}

1. King K, Farmer J. What older people want: evidence from a study of remote Scottish communities. Rural Remote Health. 2009;9:1166.

2. Dale B, Söderhamn U, Söderhamn O. Life situation and identity among older home-living people: a phenomenological-hermeneutic study. Int J Qual Stud Health Well-being. 2012;7:18456.

3. Tomstad ST, Söderhamn U, Espnes GA, Söderhamn O. Lived experiences of self-care among older, home-dwelling individuals identified to be at risk of undernutrition. J Multidiscip Healthc. 2012;5: 319-327.

4. Molarius A, Janson S. Self-rated health, chronic diseases, and symptoms among middle-aged and elderly men and women. $J$ Clin Epidemiol. 2002;55:364-370.

5. Daatland SO, Herolfsen K. The family in later part of life. In: Slagvold B, Daatland SO, editors. [Older Age, Local Variations. Results from the Norwegian Study of Life Course and Generation (NORLAG), Part 1. NOVA Rapport 15/06]. Oslo, Norway: Norsk Institutt for Forskning om Oppvekst, Velferd og Aldring; 2006. Norwegian.
6. Norwegian Ministry of Health and Care Services, Report No 47. The Coordination Reform. Proper Treatment - at the Right Place and Right Time. Oslo, Norway: Norwegian Ministry of Health and Care Services; 2009.

7. Söderhamn O. Potential for Self-care. Assessing and Describing Selfcare Ability among Elderly People. Dissertation. Linköping, Sweden: Department of Medicine and Care, Division of Nursing Science, Faculty of Health Sciences, Linköping University; 1998.

8. Orem DE. Nursing. Concepts of Practice, 6th ed. St Louis, MO: Mosby Inc; 2001

9. Cohen-Mansfield J, Jensen B. Adequacy of spouses as informants regarding older persons' self-care practices and their perceived importance. Fam Syst Health. 2007;25:53-67.

10. Tomstad ST, Söderhamn U, Espnes GA, Söderhamn O. Living alone, receiving help, helplessness, inactivity are strongly related to risk of undernutrition among older home-dwelling people. Int J Gen Med. 2012;5:231-240.

11. Söderhamn U, Christensson L, Idvall E, Johansson AK, BachrachLindström M. Factors associated with nutritional risk in 75-year-old community living people. Int J Older People Nurs. 2012;7:3-10.

12. Wham C, Carr R, Heller F. Country of origin predicts nutrition risk among community living older people. J Nutr Health Aging. 2011;15: $253-258$.

13. Ülger Z, Halil M, Kalan I, Yavus BB, Cankurtaran M, Güngör, Ariogûl S. Comprehensive assessment of malnutrition risk and related factors in a large group of community-dwelling older adults. Clin Nutr. 2010;29: $507-511$.

14. Glass N, Moss C, Ogle KR. A person-centered lifestyle change intervention model: working with older people experiencing chronic illness. Int J Nurs Pract. 2012;18:379-387.

15. Fenge LA. Empowerment and community care - projecting the 'voice' of older people. J Soc Welfare Fam Law. 2001;23:427-439.

16. Yin RK. Case Study Research. Design and Methods, 3rd ed. Thousand Oaks, CA: Sage Publications; 2003.

17. Söderhamn U, Söderhamn O. Developing and testing the Nutritional Form For the Elderly. Int J Nurs Pract. 2001;7:336-341.

18. Söderhamn U, Söderhamn O. Reliability and validity of the Nutritional Form for the Elderly (NUFFE). $J A d v$ Nurs. 2002;37:28-34.

19. Söderhamn U, Flateland S, Jessen L, Söderhamn O. Norwegian version of the Nutritional Form for the Elderly: sufficient psychometric properties for performing institutional screening of elderly patients. Nutr Res. 2009;29:761-767.

20. Söderhamn O, Ek A-C, Pörn I. The Self-care Ability Scale for the Elderly. Scand J Occup Ther. 1996;3:69-78.

21. Söderhamn O, Lindencrona C, Ek A-C. Validity of two self-care instruments for the elderly. Scand J Occup Ther. 1996;3:172-179.

22. Tomstad ST, Söderhamn U, Espnes GA, Söderhamn O. Testing two selfcare-related instruments among older home-dwelling people in Norway. Int J Older People Nurs. January 25, 2012. [Epub ahead of print.]

23. Lorensen M, Evers GCM, Isenberg MA, Van Achterberg T. Crosscultural testing of the "appraisal of self-care agency: ASA scale" in Norway. Int J Nurs Stud. 1993;30:15-23.

24. Antonovsky A. Unraveling the Mystery of Health. How People Manage Stress and Stay Well, 1st ed. San Francisco, CA: Jossey-Bass Inc; 1987.

25. Söderhamn O, Evers G, Hamrin E. A Swedish version of the Appraisal of Self-Care Agency (ASA) scale. Scand J Caring Sci.1996;10:3-9.

26. Evers GCM. Appraisal of Self-care Agency. ASA scale. Dissertation. Assen/Maastricht, The Netherlands: Van Gorcum; 1989.

27. Antonovsky A. Health, Stress and Coping. London, UK: Jossey-Bass Inc; 1982.

28. Graneheim UH, Lundman B. Qualitative content analysis in nursing research: concepts, procedures and measures to achieve trustworthiness. Nurse Educ Today. 2004;24:105-112.

29. World Medical Association Declaration of Helsinki. Ethical Principles for Medical Research Involving Human Subjects. Seoul: WMA; 2008. Available from: http://www.wma.net/en/30publications/10policies/b3/ index.html. Accessed March 15, 2013. 
30. Beauchamp TL, Childress JF. Principles of Biomedical Ethics, 6th ed. New York, NY: Oxford University Press; 2009.

31. Söderhamn U, Söderhamn O. A successful way for performing nutritional nursing assessment in older patients. J Clin Nurs. 2009;18:431-439.

32. Barnes M, Bennet G. Frail bodies, courageous voices: older people influencing community care. Health Soc Care Community. 1998;6: $102-111$.

33. Giorgi A. The Descriptive Phenomenological Method in Psychology. A Modified Husserlian Approach. Pittsburg, PA: Duquesne University Press; 2009.

34. Asai JL. Nutrition and the geriatric rehabilitation patient: challenges and solutions. Topics in Geriatr Rehabil. 2004;20:34-45.

35. Pirlich M, Lochs H. Nutrition in the elderly. Best Pract Res Clin Gastroenterol. 2001;15:869-884.
36. Locher JL, Ritchie CS, Robinson CO, Roth DL, West DM, Burgio KL. A multidimensional approach to understanding under-eating in homebound older adults: the importance of social factors. Gerontologist. 2008; $48: 223-234$.

37. Jeejeebhoy KN. Nutritional assessment. Nutrition. 2000;16:585-590.

38. Söderhamn U, Dale B, Sundsli K, Söderhamn O. Nutritional screening of older home-dwelling Norwegians - a comparison between two instruments. Clin Interv Aging. 2012;7:383-391.

39. Söderhamn U, Dale B, Söderhamn O. Narrated lived experiences of self-care and health among rural-living older persons with a strong sense of coherence. Psychol Res Behav Manag. 2011:4;151-158.

40. Söderhamn O. Self-care activity as a structure: a phenomenological approach. Scand J Occup Ther. 2000;7:183-189.
Clinical Interventions in Aging

\section{Publish your work in this journal}

Clinical Interventions in Aging is an international, peer-reviewed journal focusing on evidence-based reports on the value or lack thereof of treatments intended to prevent or delay the onset of maladaptive correlates of aging in human beings. This journal is indexed on PubMed Central, MedLine, the American Chemical Society's 'Chemical Abstracts

\section{Dovepress}

Service' (CAS), Scopus and the Elsevier Bibliographic databases. The manuscript management system is completely online and includes a very quick and fair peer-review system, which is all easy to use. Visit $\mathrm{http} / / / \mathrm{www}$.dovepress.com/testimonials.php to read real quotes from published authors.

Submit your manuscript here: http://www.dovepress.com/clinical-interventions-in-aging-journal 